\title{
Effects of intertrial reward and/or nonreward placements during a 20 -second intertrial interval on single-alternation training in rats
}

\author{
JOSEPH J. FRANCHINA and JOSEPH X. RICE \\ Virginia Polytechnic Institute and State University, Blacksburg, Virginia 24061
}

\begin{abstract}
Seventy male hooded rats received single-alternation runway training in which goalbox placements were interpolated during the 20-sec intertrial interval. Placements provided alternating reward/ nonreward, random reward/nonreward, continuous reward, or continuous nonreward. Relative to nonplaced controls, alternation performance was reliably facilitated only by intertrial alternation placements which re-presented the goal event of each immediately preceding instrumental trial. All other intertrial procedures reliably impaired alternation performance. Degree of impairment was graded from least to most as follows: intertrial alternation placements with the goal event opposite to that of each immediately preceding instrumental trial, intertrial placements with continuous nonreward, intertrial placements with continuous reward, and intertrial placements with random reward/nonreward.
\end{abstract}

Capaldi $(1967,1971)$ proposes that the stimulus aftereffects of reward or nonreward from one instrumental trial remain available for conditioning to subsequent instrumental behavior until such aftereffects are replaced by those of the next reward/ nonreward event. The effects of replacing aftereffects stimuli have been investigated, particularly in relation to experimental extinction, in studies which employed intertrial goalbox placements. For example, rewarded or nonrewarded goalbox placements interpolated between instrumental training trials reliably influence the size of the partial reinforcement extinction effect (Capaldi, Hart, \& Stanley, 1963; Capaldi \& Spivey, 1963, 1964; Homzie, Rudy, \& Carter, 1970; Spence, Platt, \& Matsumoto, 1965).

Although the effects of intertrial placements on extinction presumably reflect the conditioning of stimulus aftereffects to performance during instrumental training (Capaldi, 1967), relatively little data have been reported on the effects of intertrial events on response acquisition. What data are available have been provided by Homzie and his colleagues (e.g., Homzie, Gohmann, \& Hall, 1971; Homzie et al., 1970). The present experiment investigated the influence of intertrial events on response acquisition by studying the effects of interpolating goalbox placements among training trials of a single alternation (SA) schedule of reward and nonreward.

Reprint requests should be addressed to J. J. Franchina, Department of Psychology, Virginia Polytechnic Institute and State University, Blacksburg, Virginia 24061. These data were reported at the Midwestern Psychological Association meeting, Chicago, May 1974. Thanks are due to W. B. Pavlik and L. C. Perlmuter for their critical reading of the present manuscript.
In SA training, the stimulus aftereffects of a rewarded and a nonreward trial are presumed to be conditioned differentially to subsequent instrumental responding (Capaldi, 1967), and thus responding following nonrewarded trials is faster than that following rewarded trials. If intertrial placements influence the conditioning of preceding stimulus aftereffects to subsequent instrumental performance, then interpolating placements among single alternation training trials should influence the development of differential (alternation) responding.

\section{METHOD}

\begin{abstract}
Apparatus
The apparatus was essentially that described by Franchina and Brown (1970). A wooden alleyway $(22.5 \mathrm{~cm}$ high and $9.0 \mathrm{~cm}$ wide), painted flat black, was divided by guillotine doors into a startbox (21 cm long), a runway (138 cm long), and a goalbox (14 cm long). The goalbox was attached to the runway at a $90^{\circ}$ left angle. The alleyway floor was steel rods set at $.8 \mathrm{~cm}$ apart (center to center). Each alley section had a hinged top of clear Plexiglas. An unpainted wooden box $(30 \times 30 \times 30 \mathrm{~cm})$ was located $30.8 \mathrm{~cm}$ from the side of the goalbox and served as a holding box during experimental procedures.

Photocells in circuit with timers were located 15 and $131 \mathrm{~cm}$ respectively, from the outside of the startbox door. The latter photocell was also $7 \mathrm{~cm}$ (approximately) in front of the goalbox entrance. Raising the startbox door activated the first timer Interruption of the first photobeam stopped this timer, yielding a measure of starting time, and activated a second timer. Interruption of the second photobeam stopped the second timer and provided a measure of running time. Timers recorded performance to the nearest $.01 \mathrm{sec}$.
\end{abstract}

\footnotetext{
Subjects

Seventy experimentally naive male hooded rats, $120-130$ days old, were obtained from the colony maintained by the Department of Psychology of VPI\&SU. Throughout the experiment, the rats were housed individually and received $10 \mathrm{~g}$ of dry ground chow daily,
} 
15-20 min after experimental treatments. Water was continually available ad lib.

\section{Procedures and Design}

On Day 1 , all rats were started on the feeding regimen ( $10 \mathrm{~g}$ daily), and on Days 1-4, each rat was handled for 2-3 min per day. On Days 5 and 6, each rat received alley exploration, 5 min on Day 5 and $3 \mathrm{~min}$ on Day 6. After exploration on Day 6, the rats were randomly assigned to experimental groups, 10 rats per group. On Day 7 all rats were started on 16 days of runway training under an alternation schedule of reward and nonreward. Each rat received 10 training trials per day except for training Days 1 and 2 when four and six trials, respectively, were administered. For a trial the rat was placed into the startbox. After $5 \mathrm{sec}$, the guillotine door was raised and the rat was allowed $40 \mathrm{sec}$ to enter the goalbox. If the rat entered the goalbox, the goalbox door was closed immediately and the rat was confined for $20 \mathrm{sec}$. On rewarded trials, the rat received wet mash in a glass goal cup $(3.8 \mathrm{~cm}$ in diameter and $1.9 \mathrm{~cm}$ deep). On nonrewarded trials, a highly similar glass cup was present in the goalbox, but this cup was empty. If the rat did not enter the goalbox within $\mathbf{4 0 ~ s e c , ~ t h e ~ g o a l - ~}$ box door was closed and the rat was placed directly into the goalbox for the confinement condition. On such trials, a latency of $\mathbf{4 0 ~ s e c}$ was recorded. After each training trial, the rat was removed from the goalbox to the holding box for the start of the intertrial interval (ITI). The ITI was $20 \mathrm{sec}$, excluding the $2-3 \mathrm{sec}$ that elapsed when the experimenter transported the rat (by hand) for intertrial procedures. All intertrial placements and control procedures began after $10 \mathrm{sec}$ of the ITI had elapsed. For a placement, the rat was removed from the holding box and was placed into the goalbox, head down, directly over the goal cup. Goalbox confinement lasted $10 \mathrm{sec}$. After $10 \mathrm{sec}$, the rat was removed from the goalbox and was immediately placed into the startbox of the alleyway for the next instrumental trial. There were five intertrial-placement groups. The repetition (Rep) and the reverse (Rev) groups received intertrial goalbox placements which alternated reward and nonreward. For Rep, each placement repeated the goal event of the immediately preceding training trial; for Rev, each placement provided the goal event opposite to that of the immediately preceding trial (e.g., a nonrewarded placement followed a reward training trial). The continuous reward (CR) and the continuous nonreward $(C N)$ groups received rewarded and nonrewarded placements, respectively, between all training trials. The random $(\mathrm{Rm})$ group received a random $50 \%$ schedule of reward/nonreward in placements, with the stipulation that in each block of 20 instrumental trials reward and nonreward placements occurred equally often after rewarded and nonrewarded trials.

The placement control (PC) group received the same instrumental procedures as did the intertrial placement groups but never received any goalbox experience between training trials: after $10 \mathrm{sec}$ of the ITI had elapsed, the rat was removed from the holding box, was held on the experimenter's arm for 2-3 sec, and then returned to the holding box for $10 \mathrm{sec}$ more. Then the rat was removed to the startbox for the next instrumental trial. A second control group, RepC, underwent the same intertrial experience as $\mathrm{PC}$ but was used to evaluate the possible influence of goalbox confinement duration for Rep group. Specifically, Rep group received $20 \mathrm{sec}$ of goalbox confinement with reward (or nonreward) on an instrumental trial and, shortly after, received another $10 \mathrm{sec}$ of confinement under intertrial procedures which repeated the immediately preceding goal event. If the temporal interval between these events is momentarily ignored, then the Rep group might be viewed as receiving a total of $30 \mathrm{sec}$ of reward (or nonreward) following instrumental responding. To evaluate whether the sheer duration of reward (or nonreward) per se influenced the performance of the Rep group (e.g., relative to the $\mathrm{PC}$ group), the $\mathrm{RepC}$ control group received alternation runway training with $30 \mathrm{sec}$ of uninterrupted goalbox confinement on each trial. In this experiment, temporal durations of startbox and goalbox confinement, ITI, and holding-box confinement were monitored by a free-running electric timer which was reset to zero to start each timing period.

\section{RESULTS}

Figure 1 presents mean log running time in blocks of five trials following reward (TFR) and following nonreward (TFN) in the runway for each placement group and PC controls. Starting times yielded essentially similar results and will not be presented.

Relative to PC controls, alternation learning was facilitated by Rep intertrial placements and was impaired by all other placement conditions. Impairment was least for the Rev group and greatest for the $\mathrm{Rm}$ group, with $\mathrm{CN}$ and $\mathrm{CR}$ groups intermediate to these extremes. From Figure 1 it appears that the influence of intertrial placements was more marked on TFR performance than on TFN performance.

Analysis of variance over all the data of Figure 1 yielded a reliable interaction of Placement Condition by Trial Blocks by TFR/TFN, $F(70,756)=8.71$, $\mathrm{p}<.001$. Simple effects comparisons of each group with the PC group over Trial Blocks 1-15 yielded a reliable Groups by Trial Blocks by TFR/TFN interaction in each case. This finding provided reliable evidence for differential rates of alternation learning between each intertrial placement group and the nonplaced (i.e., PC) control group. The $F$ values of these analyses were $10.74,7.44,8.63,17.06$, and 19.33, respectively, for PC compared with the Rep, $\mathrm{Rev}, \mathrm{CN}, \mathrm{CR}$, and $\mathrm{Rm}$ groups respectively. All dfs were 14 and 252 ; ps were less than .001. Similar comparisons among the Rev, $\mathrm{CR}$, and $\mathrm{CN}$ groups over Trial Blocks 1-15 yielded a reliable interaction of Groups by Trial Blocks by TFR/TFN for Rev vs. $\mathrm{CN}$ and Rev vs. CR, but not for $\mathrm{CN}$ vs. $\mathrm{CR}$ $[\mathrm{F}(15,252=1.92,1.91$, and $1.32, \mathrm{p}<.05,<.05$, $>$.05]. Finally, analysis of variance for all groups on TFR and on TFN separately yielded a reliable interaction of Placement Conditions by Trial Blocks for TFR $[F(70,756)=6.73, p<.001]$ and a reliable effect of Placement Condition alone for TFN $[F(5,54)=3.18, p<.05]$. The TFN analysis yielded no reliable interaction involving Trial Blocks.

Considering the influence of intertrial placements on terminal levels of alternation performance, Figure 1 shows that over Trial Blocks 13-15 the difference in performance between TFR and TFN was largest for Rep and PC, intermediate for Rev, CN, and $\mathrm{CR}$, and smallest for $\mathrm{Rm}$. Analysis of variance over all the data for Trial Blocks 13-15 showed a reliable interaction of Placement Conditions by TFR/TFN $[F(5,54)=28.73, p<.001]$. The effect, Trial Blocks, was not reliable, and nor did it enter into any reliable interactions. This latter finding suggests that by the end of training TFR and TFN performances were asymptotic and, by implication, 
Figure 1. Mean running time in $\log$ seconds is presented in blocks of five trials for trials following reward (TFR) and for trials following nonreward (TFN) for the nonplaced control group (PC) and the various placement groups, the Rep, Rev, CR, CN, and Rm groups.

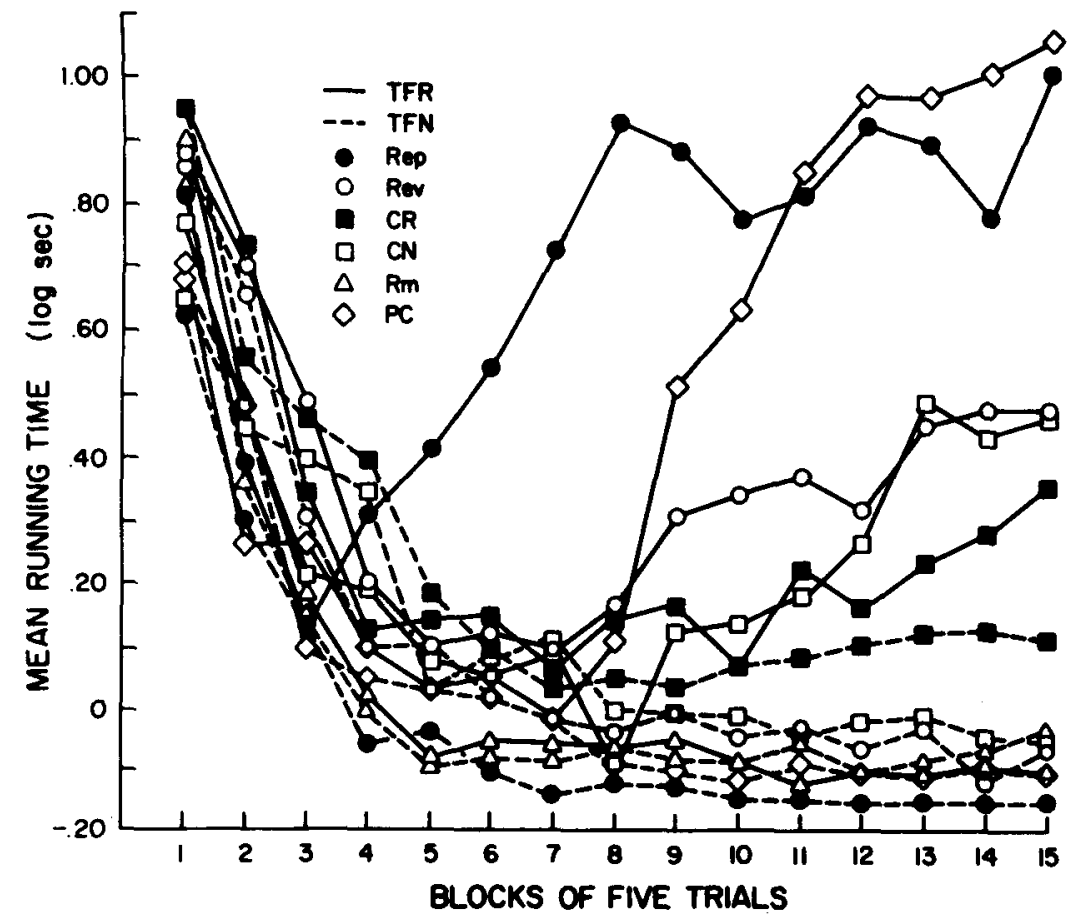

so was the terminal magnitude of alternation performance. To clarify the reliable Placement Conditions by TFR/TFN interaction, an analysis of variance evaluated TFR and TFN performance separately over Trial Blocks 13-15. A reliable effect of Placement Condition was obtained in each analysis, $F_{s}(5,54)=21.26$ and 4.74 , ps $<.001$ and $<.01$ for TFR and TFN, respectively. Subsequent Scheffé comparisons showed that for TFR Rep and PC groups did not differ reliably from each other but each of these groups differed reliably from $\mathrm{Rev}, \mathrm{CN}, \mathrm{CR}$, and $\mathrm{Rm}$ groups, respectively $(p<.05)$. The Rev, $C N$, and $C R$ groups did not differ reliably from each other; but each of these groups differed reliably from Rm group. For $T F N$, Scheffé comparisons showed that the CR group differed reliably from $R e p, P C$, and $R m$ groups $(p<.05)$. No other comparisons yielded reliable differences.

Finally, performance of the RepC control group was essentially like that of the PC group on TFR and on TFN and, hence, was not presented in Figure 1. Analysis of variance comparing RepC group with the Rep group over Trial Blocks 1-15 and, again, over Trial Blocks 13-15 yielded the same reliable effects as those indicated for comparisons between Rep and PC groups. Since RepC differed reliably from Rep but not from $P C$, it seems unlikely that the differences in performance between Rep and PC simply reflect a difference in total goalbox confinement duration (30 sec for Rep and $20 \mathrm{sec}$ for $\mathrm{PC}$ ).

\section{DISCUSSION}

In this experiment, interpolating goalbox placements between single alternation training trials reliably altered the development of differential (alternation) responding relative to nonplaced (PC) controls. In alternation training, instrumental performance is presumably conditioned differentially to distinctive stimulus aftereffects from the goal event (reward or nonreward) of the immediately preceding training trial (Capaldi, 1967). Intertrial placements influenced alternation responding in this study perhaps because the stimulus aftereffects from the intertrial goal event either reinstated or replaced the aftereffects of the goal event of the immediately prior training trial. Thereby, intertrial placements may have influenced what stimulus aftereffects were available for conditioning on the subsequent instrumental trial.

For example, Rep placements reliably facilitated alternation responding over that of PC controls because Rep procedures re-presented the goal event, and presumably the stimulus aftereffects, of each immediately prior training trial. This reinstatement procedure may then have enhanced the availability of the preceding reward (or nonreward) aftereffects (or their equivalent) for subsequent instrumental conditioning. Placements under Rev, CN, CR, and $\mathrm{Rm}$ procedures reliably impaired alternation performance relative to PC controls perhaps because these procedures provided goal events whose stimulus aftereffects replaced those from the goal 
event (reward/nonreward) of the immediately prior training trial. This replacement function may then have curtailed the extent to which distinctive stimulus aftereffects from the preceding trial were available for subsequent instrumental conditioning.

Interestingly, except for the $\mathrm{Rm}$ group, each impaired group, Rev, $C N$, and $C R$, eventually showed reliable alternation performance. This finding suggests that as training progressed there was a decrease in the replacement function of the Rev, CN, and CR intertrial procedures, and, as a result, the stimulus aftereffects from the immediately preceding goal event eventually influenced subsequent performance. Capaldi (1967), Capaldi and Spivey (1963), and Spence et al. (1965) have proposed that as the number of training trials and intertrial placements increased, intertrial goal events, and their stimulus aftereffects, may be discriminated from the goal event and aftereffects of the preceding training trial. This discrimination may be fostered either by the presence of instrumental responseproduced cues which occur on training trials but not in intertrial placements or by the occurrence of intertrial goal events and the preceding (instrumental) goal event at different points in time relative to the subsequent training trial. Following such a discrimination, the stimulus aftereffects of an intertrial placement may be less effective in replacing the aftereffects of the preceding goal event, and, thus, the latter may become increasingly available for conditioning on the next instrumental trial.

This analysis seems appropriate for the $\mathrm{CN}$ and CR groups. These intertrial procedures each provided that nondifferential stimulus aftereffects, always nonreward or always reward, were present prior to the next training trial. The eventual development of alternation performance despite continued $\mathrm{CN}$ and $\mathrm{CR}$ procedures suggests the presence of differential aftereffects, separate from those nondifferential aftereffects occasioned by $\mathrm{CN}$ or $\mathrm{CR}$ intertrial placements. Presumably the differential aftereffects involved were those from the preceding rewarded/nonrewarded alternation training trial. A similar analysis seems feasible for the Rev group. Since Rev procedures provided that each nonrewarded training trial be followed by intertrial reward and each rewarded trial, by intertrial nonreward, the stimulus aftereffects available for instrumental conditioning on the next trial may, in each case, have been a combination of both reward and nonreward aftereffects. [The plausability of this combination of aftereffects seems reasonable, especially if an intertrial goal event only incompletely replaces the aftereffect cues of the preceding trial's goal event (Capaldi, 1967; Capaldi \& Spivey, 1963).] Accordingly, the presence of combined stimulus aftereffects from reward and nonreward prior to each training trial may have constituted nondifferential cues for responding by the Rev group. The gradual development of alternation performance for the Rev group suggests the influence of differential stimulus aftereffects whose availability presumably resulted from the eventual discrimination between goal events of training trials and those of interpolated placements.

Alternation performance developed faster for the Rev group than for CN or CR and faster for the Rep group than for Rev. These results suggest that for Rev and Rep, intertrial events per se influenced alternation performance, perhaps by providing stimuli suitable for predicting the goal event coming up on the next training trial (Homzie et al., 1970, 1971). Specifically, for the Rep group, intertrial nonreward was followed by a rewarded training trial, and intertrial reward was followed by a nonrewarded trial. For the Rev group, intertrial reward was followed by a rewarded trial, and intertrial nonreward, by a nonrewarded trial. This ordering of goal events from placements to instrumental trials may have permitted the stimulus aftereffects of a placement event to function as a differential cue for responding on the next training trial. Thus, alternation performance for the Rev group (and for the Rep group) was superior to that of the $\mathrm{CN}$ or $\mathrm{CR}$ groups, whose intertrial placements continually yielded nondifferential cues for responding on the next trial. The superiority of the Rep group over the Rev group may reflect either the initial impairment of alternation performance for Rev because of the replacement function of Rev intertrial goal events or the facilitation of alternation performance for the Rep group because of the reinstatement function of Rep intertrial events. Briefly, under the Rev procedures, the replacement function of each intertrial event for the immediately preceding goal event may have provided nondifferential stimulus aftereffects prior to each trial and thereby militated against predicting the goal event coming up (at least early in training). Under Rep procedures, each intertrial goal event re-presented that of immediately preceding training trial and thus may have maintained the relative distinctiveness of stimulus aftereffects for differentially predicting the goal event coming up.

Finally, this experiment shows that intertrial reward/nonreward, which has already been shown to affect extinction performance (e.g., Capaldi \& Spivey, 1963), may also affect the establishment of differential responding in single-alternation training. Capaldi's (1971) research on response patterning does deal with the influence of sequential variables on response acquisition, but the main thrust of sequential theory seems directed towards explaining extinction responding. This explanation, in turn, is frequently stated in terms of aftereffect conditioning 
which is presumed to occur in training. The present data extend the generality of Capaldi's viewpoint outside of the extinction paradigm and yield information on aftereffect conditioning beyond that typically inferrable from extinction results.

\section{REFERENCES}

CAPALDI, E. J. A sequential hypothesis of instrumental learning. In K. W. Spence \& J. T. Spence (Eds.) The psychology of learning and motivation (Vol. 1). New York: Academic Press, 1967.

CAPALDI, E. J. Memory and learning: A sequential viewpoint. In W. K. Honig \& P. H. R. James (Eds.), Animal memory. New York: Academic Press, 1971.

Capaldi, E. J., Hart, D., \& Stanley, L. R. Effects of intertrial reinforcements on the aftereffect of nonreinforcement and resistance to extinction. Journal of Experimental Psychology, 1963, 65, 70-74.

CaPaldi, E. J., \& SPIVEy, J. E. Effect of goal-box similarity on the aftereffect of nonreinforcement and resistance to extinction. Journal of Experimental Psychology, 1963, 66, 461-465.
Capaldi, E. J., \& SpIvey, J. E. Intertrial reinforcement and aftereffects at 24-hour intervals. Psychonomic Science, 1964, 1, 181-182.

Franchina, J. J., \& Brown, T. S. Response patterning and extinction in rats with hippocampal lesions. Journal of Comparative and Physiological Psychology, 1970, 70, 66-72.

Homzie, M. J., Gohmann, T., \& Hall, S. W., JR. Runway performance in rats as determined by the predictive value of intertrial reinforcements. Journal of Comparative and Physiological Psychology, 1971, 74, 90-95.

Homzie, M. J., Rudy, J. W., \& CARTER, E. N. Runway performance in rats as a function of goal-box placements and goal-event sequences. Journal of Comparative and Physiological Psychology, 1970, 71, 283-291.

Spence, K. W., Platt, J. R., \& Matsumoto, R. Intertrial reinforcement and the partial reinforcement effect as a function of number of training trials. Psychonomic Science, 1965, 3, 205-206.

(Received for publication May 27, 1975; revision accepted June 23,1976 .) 